\title{
Accidental ethyl mercury poisoning with nervous system, skeletal muscle, and myocardium injury
}

\author{
I CINCA, IRINA DUMITRESCU, P ONACA, A SERBĂNESCU, AND B NESTORESCU \\ From the Clinic of Neurology and the Laboratory of the Clinic of Occupational Diseases, \\ Colentina Hospital, Bucharest, Romania
}

SUMMARY Four case reports are presented of patients who ate the meat of a hog inadvertently fed seed treated with fungicides containing ethyl mercury chloride. The clinical, electrophysiological, and toxicological, and in two of the patients the pathological data, showed that this organic mercury compound has a very high toxicity not only for the brain, but also for the spinal motoneurones, peripheral nerves, skeletal muscles, and myocardium.

Use of organic mercury compounds as fungicides has been noted in several countries to produce severe poisoning, occasionally epidemic in character. We had the opportunity to examine the first cases of such poisoning ever to have appeared in Romania. They showed some features not yet described in the literature on poisoning with various organic mercury compounds.

\section{Case reports}

In August 1974, a mother with her three children was referred to our clinic by a provincial hospital where they had treated for 17 days.

\section{CASE 1}

This boy (MG), aged 15 years, one week before his first admission developed pain in the muscles and gait disturbance. He could neither stand nor walk. The tendon jerks were bilaterally hyperactive and there was a positive Babinski's sign on the left side, clonus of the left foot, and twitching of the thigh muscles. Severe cerebellar signs were noted-that is, ataxia and dysarthria. Within a week he developed dysphagia and aphonia, Bábinski's sign appeared bilaterally, and the overall status deteriorated. On referral to this clinic we noted generalised muscle wasting, spasticity of the upper limb flexors and lower

Address for reprint requests: Professor I Cinca, Str Andrei Muresan 6, Sector I, Bucharest 71276, Romania.

Accepted 21 May 1979 limb extensors, bilateral mydriasis, and impaired swallowing. The patient was drowsy, unresponsive to commands, and had loss of sphincter control. The clinical picture deteriorated even further: he developed a horizontal nystagmus, was agitated, and became comatose four days later. $\mathrm{He}$ required ventilatory assistance and died three days later from cardiac arrest, within one month of the onset of the illness.

The CSF was clear with 0.4 lymphocytes per $\mathrm{mm}^{3}$ and $0.28 \mathrm{~g} / 1$ albumin. Haemoglobin was $10.88 \mathrm{~g} / \mathrm{dl}$. The leucocyte count was $13500 / \mathrm{mm}^{3}$ with neutrophilia. The blood glucose was $8.6 \mathrm{mmol} / 1$, urea $17.3 \mathrm{mmol} / 1$, creatinine $248.5 \mu \mathrm{mol} / 1$, sedimentation rate $55 \mathrm{~mm}$ in the first hour, $90 \mathrm{~mm}$ in the second hour. There were traces of albumin in the urine.

An electroencephalogram showed slow diffuse dysrhythmia with predominance of delta waves.

General necropsy revealed foci of bronchopneumonia and an abscess of the left lung. The gross appearance of the brain was normal. All over the cerebral cortex but mostly in the calcarine cortex, there was nerve cell loss and a diffuse proliferation of neuroglia on microscopic examination of the brain.

In the midbrain and bulbar (especially the lateral nucleus) reticular formation, neuroglia activation with nerve cell satellitosis was apparent, extending to neuronal loss and formation of neuronophagic nodules.

Myelin preparations showed demyelination of the nerve fibres in the ninth and tenth cranial nerve roots (fig 1) In the cerebellum there was 


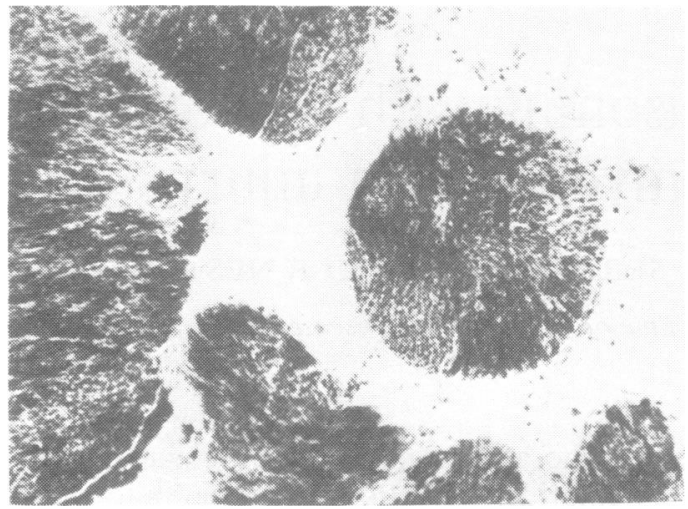

Fig 1 Demyelination of nerve fibre bundles in the vagus nerve roots (case 1). Spielmeyer staining, original magnification $\times 100$.

cell wasting of the granular layer. Purkinje's cells were more spared, though in certain areas silver impregnation for neurofibrils showed empty basket-cells and torpedo-shaped Purkinje cell axons (fig 2). The lesions were evenly distributed over the neo- and paleocerebellar cortex. Throughout its length the spinal cord showed a highly abnormal picture of the ventral horns, with motoneurone loss and presence of neurophagocytic nodules (fig 3). Among the spared neurones many showed chromatolysis or were shrunken or hyperchromatic. The spinal and peripheral nerve roots were normal in appearance.

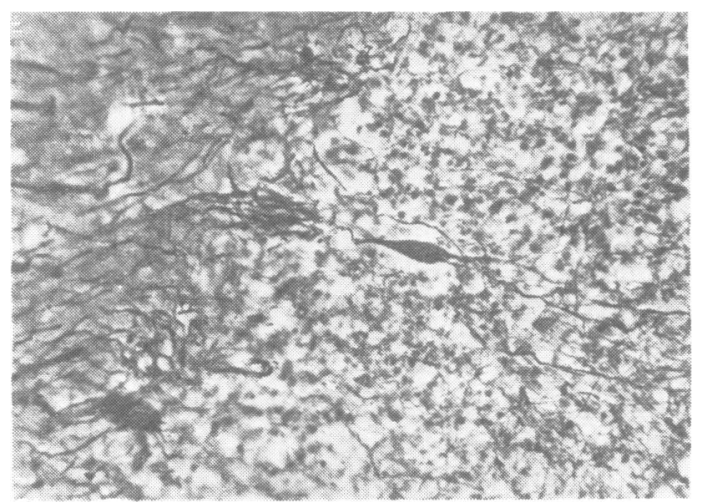

Fig 2 Empty basket-cells and torpedo-like axon of Purkinje cell in cerebellar cortex (case 1). Silver impregnation Bielschowsky, original magnification $\times 240$.

The skeletal (intercostal) muscles showed zones of waxy segmental degeneration of the muscle fibre, with interstitial proliferation of fibroblasts (fig 4).

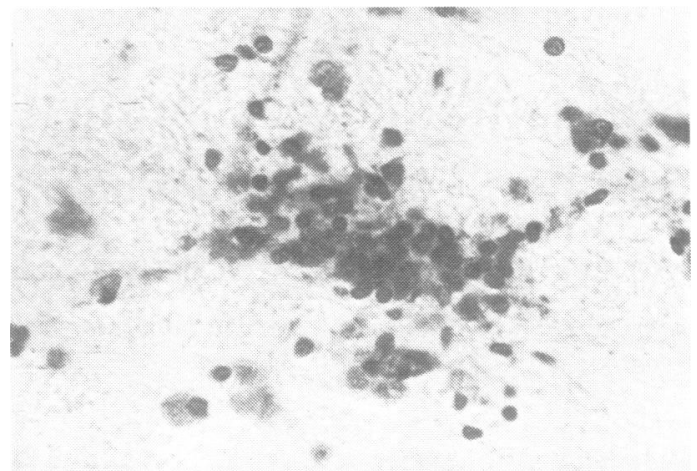

Fig 3 Neuronophagic nodule in spinal cord ventral horn (case 1). Nissl staining, original magnification $\times 400$.

On microscopic examination of the other viscera, the kidney showed stasis and interstitial infiltration, with rarefaction of the glomerular elements here and there. The myocardium showed zones of interstitial chronic myocarditis with proliferation of fibroblasts but absence of sclerosis (fig 5). In the lung bronchopneumonic foci were found. The liver was normal.

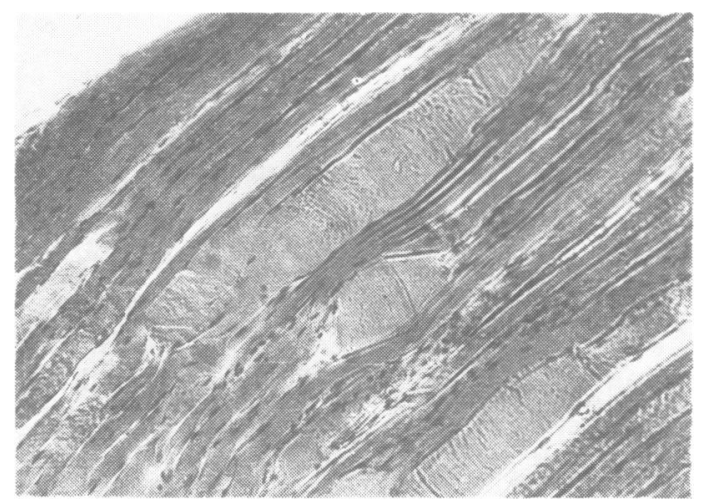

Fig 4 Intercostal muscle (case 1). Waxy degeneration o/ muscle fibre segments with interstitial fibroblast proliferation. Haematoxyline and eosine staining, original magnification $\times 100$.

\section{CASE 2}

This 10 year old boy (MM) had, five days before admission, developed walking difficulty, muscle pains, vomiting, and dysarthria. Neurological examination showed walking disability, weakness of the limbs, general hypotonia, horizontal nystagmus, deglutition impairment, severe ataxia, and increased tendon reflexes. 


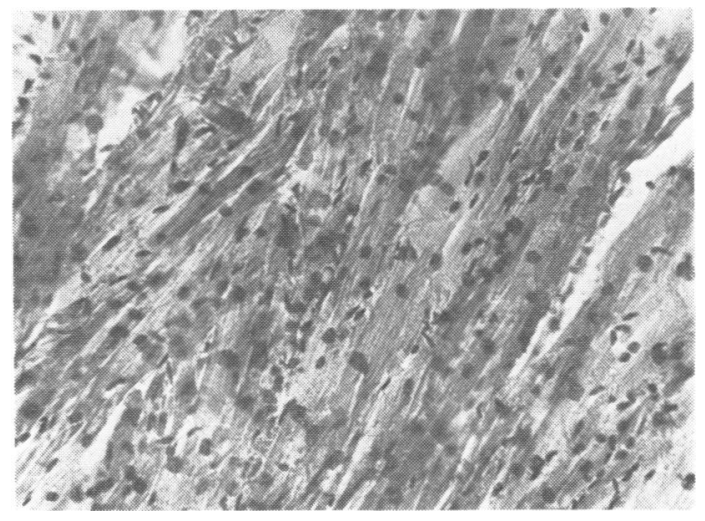

Fig 5 Interstitial chronic myocarditis with fibroblast proliferation (case I). Haematoxyline and eosine staining original magnification $\times 240$.

Over the next two weeks he developed psychomotor agitation and a bilateral Babinski sign. He became unable to speak and entered a subcoma state.

$\mathrm{He}$ was still comatose when referred here. He could not swallow, the pupils were bilaterally dilated, and there was generalised muscle atrophy and loss of sphincter control. His condition deteriorated gradually. Within 10 days he developed decortication posturing, fever, and vomiting. He died from cardiac arrest within a month and a half of the onset of the disease.

The CSF was clear, with 0.8 lymphocytes $/ \mathrm{mm}^{3}$; albumin $0.16 \mathrm{~g} / \mathrm{l}$; blood contained $10.22 \mathrm{~g} / \mathrm{dl}$ haemoglobin. The white cell count was $10000 /$ $\mathrm{mm}^{3}$ with neutrophilia. Blood urea was at first $6.7 \mathrm{mmol} / \mathrm{l}$ and then increased to $19.7 \mathrm{mmol} / \mathrm{l}$.

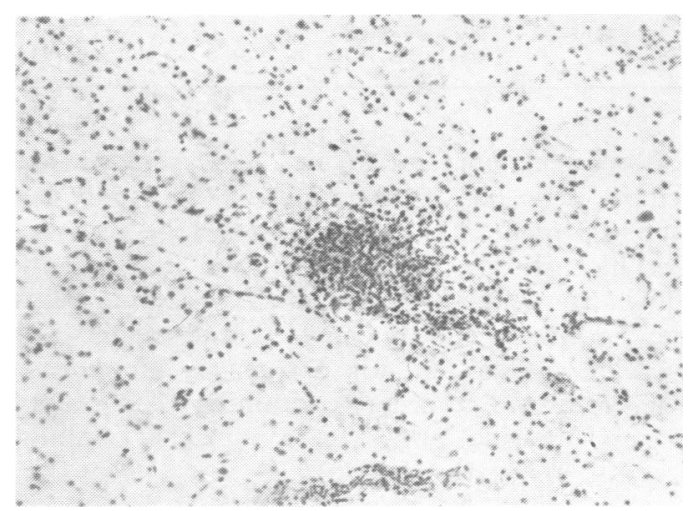

Fig 6 Calcarine cortex: disappearance of neurones with intense neuroglial proliferation and formation of neuroglial nodules (case 2). Nissl staining, original magnification $\times 100$.
Sedimentation rate was $27 \mathrm{~mm} / \mathrm{hr}$; urine albumin level was $3 \cdot 3 \mathrm{~g} / 1$.

Electrocardiography showed S-T segment depression and $\mathrm{T}$ wave inversion in precordial leads. The electroencephalogram was of average voltage with lack of alpha rhythm and diffuse slow activity.

On gross pathological examination, the brain appeared normal. Microscopic examination of the cerebral cortex showed lesions which were identical to those found in case 1 but with a much more intense neuroglial proliferation that had resulted in formation of neuroglial nodules in the calcarine area (fig 6).

The caudate nucleus and the putamen showed an almost complete loss of the small cells with preservation of most of the large cells and diffuse proliferation of glia. In the brainstem there was glial proliferation in the midbrain periaqueductal grey matter. In the cerebellum cell loss was noted in the granular layer. The spinal cord showed alterations identical to those found in case 1 .

Pathological examination of the viscera revealed acute inflammation of the renal pelvis, stasis and tiny lesions of interstitial nephritis.

Chronic interstitial myocarditis lesions were found as in case 1 (fig 7).

In the lung there was a picture of oedematous alveolitis. The liver was normal.

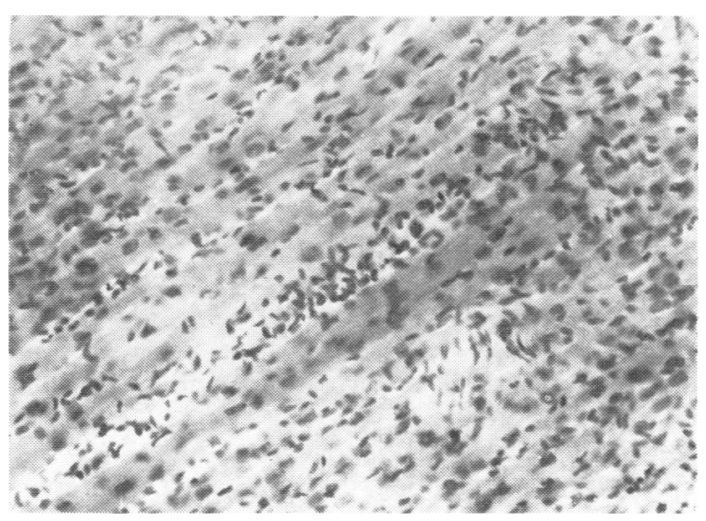

Fig 7 Interstitial chronic myocarditis (case 2).

Haematoxyline and eosine staining, original magnification $\times 240$.

CASE 3

The mother (MT), a 48 year old farmer, when admitted to the hospital accompanying her two sons had no pathological sign whatever. Within 48 hours she developed gait disturbances with 
progressive weakness in the lower limbs and muscular pains. Referred to this clinic, she was noticed to have spastic paraparesis, with bilateral Babinski sign and distal superficial hypoaesthesia of the limbs. She was drowsy. Nine days later she developed headache and vomiting, her sight deteriorated and there was a horizontal nystagmus and intention tremor. She became agitated, confused and delirious. Within one month of the onset of symptoms she improved and was able to walk again. The pyramidal tract signs remitted and so did the mental disturbance. She continued to have headache and fatigue. The visual field was concentrically narrowed.

Routine laboratory tests failed to show any abnormality, except a slightly raised blood urea $(7 \cdot 3 \mathrm{mmol} / \mathrm{l})$, while in the CSF there was a slight pleocytosis (15 lymphocytes $/ \mathrm{mm}^{3}$ ) with an albumin level of $0.3 \mathrm{~g} / 1$.

Electrocardiography showed flattening of the $\mathrm{T}$ wave in precordial leads. An audiogram revealed slight bilateral perceptive deafness. The EEG tracing was of slighly decreased amplitude, with the alpha rhythm present and predominance of fast waves.

Two months later she was discharged home much improved. She was readmitted for a review four months later and was found to show only a concentric narrowing of the visual fields.

\section{CASE 4}

This 15 year old girl (MA), was admitted one week after her brother. Five days previously she had developed gait and sight impairment and a state of drowsiness. Her gait was spastic and slightly ataxic. Babinski's sign was present on both sides. Speech was dysarthric.

When examined here she was found to have marked amblyopia with bilateral mydriasis and slow pupillary reflexes. She could walk only if supported. Her gait was spastic and she had spastic quadriparesis, drowsiness and disturbed sphincter control. Three days later, vomiting, intention tremor, staccato speech, and slowness cerebration developed. Within 10 days of admission the motor deficiency remitted, she regained the ability to distinguish the shape of things, though she still had concentric narrowing of the visual fields. She recovered progressively; her sight improved as she was now able to see at $5 \mathrm{~m}$ distance. She started to walk again and the cerebellar signs diminished.

The CSF contained no cells, albumin $0.16 \mathrm{~g} / 1$. Urine albumin was noted at a concentration of $0.5 \mathrm{~g} / 1$.
Her electrocardiogram showed sinus rhythm at 100 beats $/ \mathrm{min}$. In precordial leads the $\mathrm{S}-\mathrm{T}$ segment was below the isoelectric line and the $T$ wave was negative. There was evidence of left ventricular hypertrophy. The electroencephalogram showed slow dysrhythmia.

The diagnosis established during hospitalisation was organic mercury poisoning, and treatment with penicillamine $1 \mathrm{~g} /$ day for 21 days was started one month after admission. She was discharged greatly improved after a stay of two months in the clinic. When reviewed four months later she still had a mild intention tremor and concentric narrowing of the visual fields.

The clinical diagnosis of organic mercury poisoning was confirmed by the toxicological determinations performed on the blood, hair and urine immediately after admission (tables 1,2 ).

Table 1 Mercury content of blood and hair

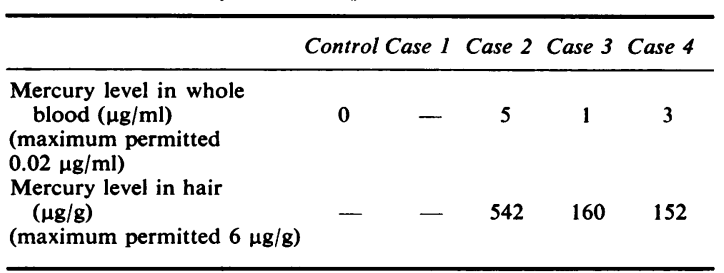

Table 2 Mercury in the urine ( $\mu \mathrm{g} / 24 \mathrm{hr}$; maximum permitted $100-120 \mu \mathrm{g} / 24 \mathrm{hr}$ )

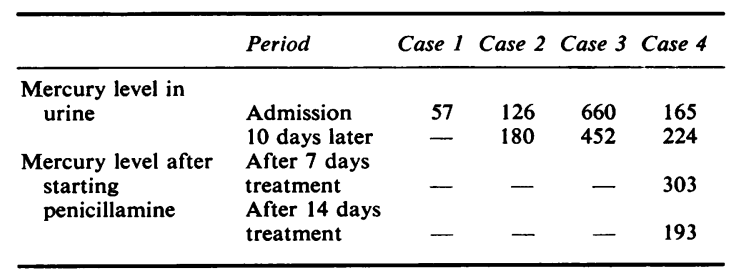

Subsequent epidemiological data showed that 10 days or so before becoming ill the family had eaten the meat of a hog that over the past few days had shown signs of disease, reeling and falling. Some poultry died with the same signs. They had inadvertently been fed seed treated with fungicides containing alkyl mercury compounds - Cryptodin (a powder containing $2.5 \%$ ethyl mercury chloride) and F. $B_{7}$ (a powder containing $1 \%$ ethyl mercury chloride).

ELECTROPHYSIOLOGICAL INVESTIGATION In the two surviving patients the following additional investigations were performed. 
In cases 3 and 4 EMG recordings were obtained from the tibialis anterior, extensor digitorum brevis of the foot and the first dorsal interosseous muscle of the hands. They were all normal.

Motor conduction velocity in cases 3 and 4 was measured in the median and ulnar nerves (segment elbow to wrist) and in the peroneal nerve (segment knee to ankle). Standard techniques were used with recording of the evoked responses in the abductor pollicis brevis, hypothenar, and extensor digitorum brevis muscles respectively.

Sensory conduction velocity was measured in the median and ulnar nerves. The stimuli were delivered to digits 1 and 5 respectively through ring electrodes. Recordings were made from the nerves at elbow and wrist. The results are shown in table 3.

Table 3 Nerve conduction velocity

\begin{tabular}{|c|c|c|}
\hline & $\begin{array}{l}\text { Immediately } \\
\text { after } \\
\text { admission }\end{array}$ & $\begin{array}{l}\text { Six months } \\
\text { later }\end{array}$ \\
\hline $\begin{array}{l}\text { Motor conduction velocity } \\
\text { Median nerve (elbow to wrist) }\end{array}$ & $m / s$ & $m / s$ \\
\hline $\begin{array}{r}\text { case } 3 \\
\text { case } 4\end{array}$ & $\begin{array}{l}60 \\
62\end{array}$ & - \\
\hline \multicolumn{3}{|l|}{ Ulnar nerve (elbow to wrist) } \\
\hline $\begin{array}{r}\text { case } 3 \\
\text { case } 4\end{array}$ & $\begin{array}{l}55 \\
60\end{array}$ & - \\
\hline \multicolumn{3}{|l|}{ Peroneal nerve (knee to ankle) } \\
\hline case 3 & 47 & - \\
\hline case 4 & 55 & - \\
\hline \multicolumn{3}{|l|}{$\begin{array}{l}\text { Sensoly conduction velocity } \\
\text { Median nerve (elbow to wrist) }\end{array}$} \\
\hline case 3 & 38 & 59 \\
\hline case 4 & 26 & 56 \\
\hline \multicolumn{3}{|l|}{ Ulnar nerve (elbow to wrist) } \\
\hline case 3 & 42 & 60 \\
\hline case 4 & 30 & 58 \\
\hline
\end{tabular}

TOXICOLOGICAL INVESTIGATIONS

The level of mercury in the blood was measured by an ultraviolet spectrometer method (table 1).
The levels of mercury in the hair, urine, and (in lethal cases) in the nervous system (table 4) and viscera (table 5), were measured by a photometric method with dithizone after decay of the organic substances in an acid oxidant (Nestorescu's method ${ }^{1}$ ). Unfortunately we were not able to use more reliable methods (atomic absorption and gas chromatography).

\section{Discussion}

In all our patients the symptoms appeared at least 10 days after ingestion of mercury contaminated foodstuffs, as reported also by other authors in organic mercury poisoning. ${ }^{2-5}$

The initial symptoms were headache, fever, diarrhoea, vomiting and myalgia, recalling especially the symptomatology in a report on poisoning by an ethyl mercury compound (ethyl mercury $p$-toluene sulphonanilide) in the 1961 Iraq epidemic. ${ }^{6}$

Although the neurological symptoms of poisoning by alkyl mercury compounds are well known especially after the 1953 Minamata epidemic, it might be of interest to attempt to correlate certain phenomena noticed in our patients with the anatomical lesions and the electrophysiological data. Thus, gross cerebellar damage was moderate, as noted by other authors. According to Okinaka et $a l^{7}$ the extensive cortical damage might also contribute to producing ataxia. The gross phonation and deglutition in case 1 might have been the result not only of the bilateral pyramidal lesions but also of demyelination in the ninth and tenth cranial nerves. We have been unable to find previous reports of the latter. It is only experimentally in animals with induced poisoning by methyl mercury compounds that lesions could be produced in the dorsal roots of the spinal nerves. ${ }^{2} 89$

Table 4 Mercury in nervous system (wet tissue; $\mu \mathrm{g} / \mathrm{g} ;$ maximum permitted $0.6 \mu \mathrm{g} / \mathrm{g}$ )

\begin{tabular}{|c|c|c|c|c|c|c|c|c|c|c|c|}
\hline & $\begin{array}{l}\text { Occipital } \\
\text { cortex }\end{array}$ & $\begin{array}{l}\text { Cerebellar } \\
\text { cortex }\end{array}$ & $\begin{array}{l}\text { Frontal } \\
\text { cortex }\end{array}$ & $\begin{array}{l}\text { Lenticular } \\
\text { nucleus }\end{array}$ & Thalamus & $\begin{array}{l}\text { Optic } \\
\text { nerve }\end{array}$ & $\begin{array}{l}\text { Centrum } \\
\text { ovale }\end{array}$ & $\begin{array}{l}\text { Choroid } \\
\text { plexuses }\end{array}$ & Pons & $\begin{array}{l}\text { Spinal } \\
\text { cord }\end{array}$ & Callosum \\
\hline $\begin{array}{l}\text { Case } 1 \\
\text { Case } 2\end{array}$ & $\overline{21.3}$ & $\overline{13.9}$ & $\begin{array}{l}22 \\
10.6\end{array}$ & $\overline{10.6}$ & $\overline{7.2}$ & $\overline{7.0}$ & $\overline{6.6}$ & $\overline{6.3}$ & $\overline{4.3}$ & $\overline{4.2}$ & $\overline{3.5}$ \\
\hline
\end{tabular}

Table 5 Mercury in viscera (wet tissue; $\mu g / g$ )

\begin{tabular}{|c|c|c|c|c|c|c|c|c|}
\hline & Kidney & Adrenal & Liver & Stomach & Lung & Spleen & Myocardium & $\begin{array}{l}\text { Skeletal } \\
\text { muscle }\end{array}$ \\
\hline $\begin{array}{l}\text { Case } 1 \\
\text { Case } 2\end{array}$ & $\begin{array}{l}28.6 \\
84.0\end{array}$ & $\overline{28.3}$ & $\overline{28.2}$ & $\overline{23.3}$ & $\overline{18.2}$ & $\overline{10.0}$ & $\overline{6.7}$ & $\overline{4.2}$ \\
\hline
\end{tabular}


Sensory disturbances have also been disclosed by the slowing down of sensory nerve conduction in cases 3 and 4 found on admission which became normal six months later on clinical recovery (table 3). Electrophysiological data have hitherto invalidated the hypothesis of peripheral neuropathy produced by methyl mercury poisoning. ${ }^{10}$

Wasting of muscles and twitching in cases 1 and 2 were suggestive of spinal cord anterior horn lesions, which were confirmed by the anatomical evidence. Poisoning by methyl mercury compounds has only very infrequently been noted to produce spinal lesions and these usually spare the ventral horn neurones. ${ }^{11}$ Yet in cases of poisoning with other organic mercury compounds, appearances like amyotrophic lateral sclerosis have been noted, as for example in ethyl phenyl mercury poisoning ${ }^{12}$ and in poisoning with ethyl mercury compounds. ${ }^{13}$ Okinaka et $a l^{7}$ consider that organic mercury compounds, according to the chemical nature of the substance, produce two forms of poisoning, a cerebro-cerebellar and a spinal form.

Apart from the lesions located in the cerebral cortex, striate nuclei, cerebellum, and mesencephalon reported by numerous authors ${ }^{4}{ }^{74-18}$, we noticed some as yet unreported lesions. These were the neuronal lesions of the bulbar reticular formation found in case 1 which we have not found reported before, though certain modifications in the lower brainstem were suspected to occur in organic mercury poisoning by von Burg and Rustam ${ }^{10}$ in their electrophysiological studies. We also failed to find any report of anatomical damage to skeletal muscle or myocardium. It should be noted that, as we noted in our cases, electrocardiographic alterations are associated with ethyl mercuryis 19 much more frequently than with methyl mercury ${ }^{5}$ poisoning.

Toxicological determinations on our cases showed greatly raised levels of mercury in the blood, hair, and urine (tables 1 and 2). The urinary excretion appears to be a less reliable index of the severity of the poisoning, since the highest excretion of mercury was in case 3 where the course was favourable, but urinary excretion of mercury is known to be extremely variable. ${ }^{20-22}$ The levels of mercury in the blood and hair are the most reliable indices of the degree of poisoning, and they were very much increased in case 2 which had a fatal course.

The brain, which is the crucial organ in intoxication by organic mercury compounds, also showed greatly increased levels of mercury in our two necropsy cases. In case 2, when samples were taken from various regions of the central nervous system, the highest levels of mercury were found in the occipital cortex, the cerebellar cortex, the lenticular nucleus, and the frontal cortex (table 4), which were also the regions with evident anatomical lesions.

In case 4 where treatment with penicillamine was begun, urinary excretion of mercury increased and then slightly decreased, but no conclusion can be drawn concerning the effectiveness of such therapy, as case 3 also improved without it.

The published data on treatment with chelating substances in organic mercury poisoning are not conclusive either, as certain authors have failed to obtain positive effects ${ }^{1323}$ while others reported having obtained improvements. ${ }^{322}$ According to Berlin and Ullberg ${ }^{24}$ accumulation of mercury in the brain is accelerated by experimental administration of dimercaprol (BAL).

Indirect poisoning after eating the meat of hogs fed by mistake with seed treated with methyl mercury compounds has also been reported by some American authors. ${ }^{25-27}$

From study of our cases, it appears that ethyl mercury compounds display a very high toxicity not only for the brain, but also for the spinal motoneurones, peripheral nerves, skeletal muscles, and myocardium.

\section{References}

1 Nestorescu B. O noua metoda pentrue determinarea mercurului în materiale biologice. Igiena $1962 ; 11: 539-43$.

2 Hunter D, Bomford RR, Russell DS. Poisoning by methyl mercury compounds. $Q J$ Med 1940; 33:193-213.

3 Höök O, Lundgren KD, Swensson A. On alkyl mercury poisoning with a description of two cases. Acta Med Scand 1954; 150:131-7.

4 Kurland L. The outbreak of a neurologic disorder in Minamata, Japan, and its relationship to the ingestion of seafood contaminated by mercuric compounds. World Neurology 1960; 1:370-95.

5 Swensson A, Ulfvarson U. Toxicology of organic mercury compounds used as fungicides. Occup Health Rev 1963; 15:5-11.

6 Jalili MA, Abbasi AH. Poisoning by ethyl mercury toluene sulphonanilide. $\mathrm{Br} J$ Ind Med 1961; 18:303-8.

7 Okinaka S, Yoshikawa M, Mozai T et al. Encephalomyelopathy due to an organic mercury compound. Neurology (Minneap) 1964; 14: 69-76. 
8 Swensson A. Investigations on the toxicity of some organic mercury compounds which are used as seed desinfectants. Acta Med Scand $1952 ; 143: 365-84$.

9 Miyakawa T, Desimaru M, Sumiyoshi S et al. Experimental organic poisoning-pathological changes in peripheral nerves. Acta Neuropathol (Berl) 1970; 15:45-55.

10 Von Burg R, Rustam H. Electrophysiological investigation of methyl mercury intoxication in humans. Evaluation of peripheral nerve by conduction velocity and electromyography. Electroencephalogr Clin Neurophysiol 1974; 37:381-92.

11 Takeuchi $\mathrm{T}$, Morikawa $\mathrm{N}$, Matsumoto $\mathrm{H}$, Shiraishi Y. A pathological study of Minamata disease in Japan. Acta Neuropathol (Berl) 1962; 2:40-57.

12 Brown IA. Chronic mercurialism. A cause of the clinical syndrome of amyotrophic lateral sclerosis. Arch Neurol 1954; 72:674-81.

13 Kantarjian AD. A syndrome clinically resembling amyotrophic lateral sclerosis following chronic mercurialism. Neurology (Minneap) 1961; 11:639-44.

14 Hunter D, Russell DS. Focal cerebral and cerebellar atrophy in a human subject due to organic mercury compounds. J Neurol Neurosurg Psychiatry 1954; 17:235-41.

15 M:Alpine D, Araki S. Minamata disease: an unusual neurological disorder caused by contaminated fish. Lancet 1958; 2:629-31.

16 Hay WJ, Rickards AG, McMenemey WH, Cumings JN. Organic mercurial encephalopathy. J Neurol Neurosurg Psychiatry 1963; 26:199-202.
17 Matsumoto H, Koya G, Takeuchi T. Fetal Minamata disease: a neuropathological study of two cases of intrauterine intoxication by methyl mercury compound. J Neuropathol Exp Neurol 1965; 24:563-74.

18 Takeuchi T. Pathology of Minamata disease. In: Kutsuna M, ed. Study group of Minamato disease. Japan: Kumamoto University, 1968: 141-228.

19 Dahhan SS, Orfaly H. Electrocardiographic changes in mercury poisoning. Am $J$ Cardiol $1964 ; 14: 178-83$.

20 Taylor Y, Guirgis HA, Stewart WK. Investigation of a population exposed to organomercuriels seed dressings. Arch Environ Health 1969; 19:505-9.

21 Gledhill RF, Hopkins AP. Chronic inorganic mercury poisoning treated with $\mathrm{N}$-acetylPenicillamine. Br J Ind Med 1972; 29:225-8.

22 Lefèvre JP, Gil R. Encéphalopathie par organomercuriels. Sem Hop Paris 1977; 53:165-71.

23 Bakir F, Damluji SF, Amin-Zaki L et al. Methyl-mercury poisoning in Iraq: an interuniversity report. Science $1973 ; 181: 230-41$.

24 Berlin M, Ullberg S. Increased uptale of mercury in mouse brain caused by 2,3-dimercaptopropanol (BAL). Nature 1963; 197:84.

25 Storrs B, Thompson J, Fair G et al. Organic mercury poisoning. Morbidity and Mortality 1940; 19:25-6.

26 Snyder RD. Congenital mercury poisoning. $N$ Engl J Med 1971; 284:1014-16.

27 Curley A, Sedlack VA, Girling EF et all. Organic mercury identified as the cause of poisoning in humans and hogs. Science 1971; 172:65-7. 